
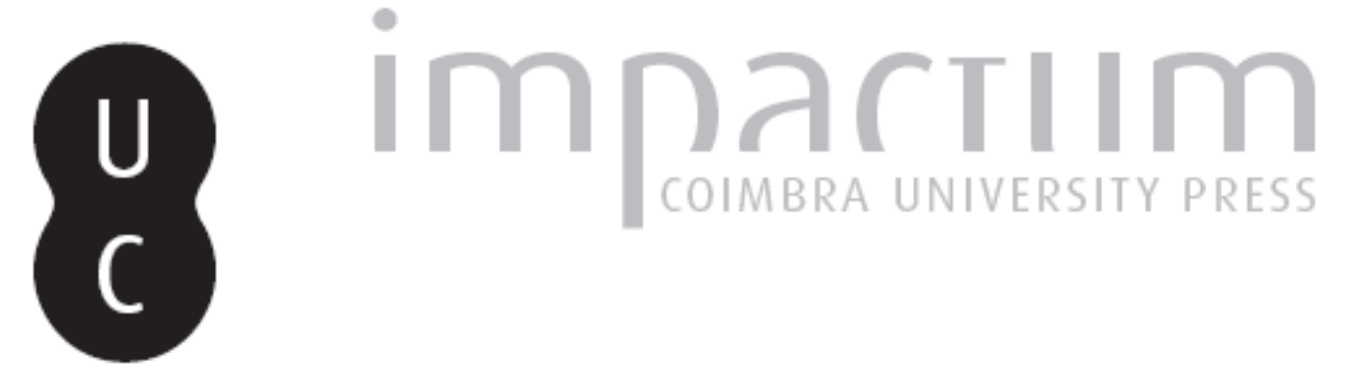

\title{
Aspetos do quotidiano e vivência feminina nos navios da carreira da Índia durante o século XVI: primeiras mulheres, buscas e sexualidade a bordo
}

Autor(es): $\quad$ Borges, Marco Oliveira

Publicado por: Imprensa da Universidade de Coimbra

URL persistente:

URI:http://hdl.handle.net/10316.2/40685

DOI:

DOI:https://doi.org/10.14195/0870-4147_47_10

Accessed : $\quad$ 26-Apr-2023 09:12:23

A navegação consulta e descarregamento dos títulos inseridos nas Bibliotecas Digitais UC Digitalis, UC Pombalina e UC Impactum, pressupõem a aceitação plena e sem reservas dos Termos e Condições de Uso destas Bibliotecas Digitais, disponíveis em https://digitalis.uc.pt/pt-pt/termos.

Conforme exposto nos referidos Termos e Condições de Uso, o descarregamento de títulos de acesso restrito requer uma licença válida de autorização devendo o utilizador aceder ao(s) documento(s) a partir de um endereço de IP da instituição detentora da supramencionada licença.

Ao utilizador é apenas permitido o descarregamento para uso pessoal, pelo que o emprego do(s) título(s) descarregado(s) para outro fim, designadamente comercial, carece de autorização do respetivo autor ou editor da obra.

Na medida em que todas as obras da UC Digitalis se encontram protegidas pelo Código do Direito de Autor e Direitos Conexos e demais legislação aplicável, toda a cópia, parcial ou total, deste documento, nos casos em que é legalmente admitida, deverá conter ou fazer-se acompanhar por este aviso.

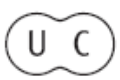




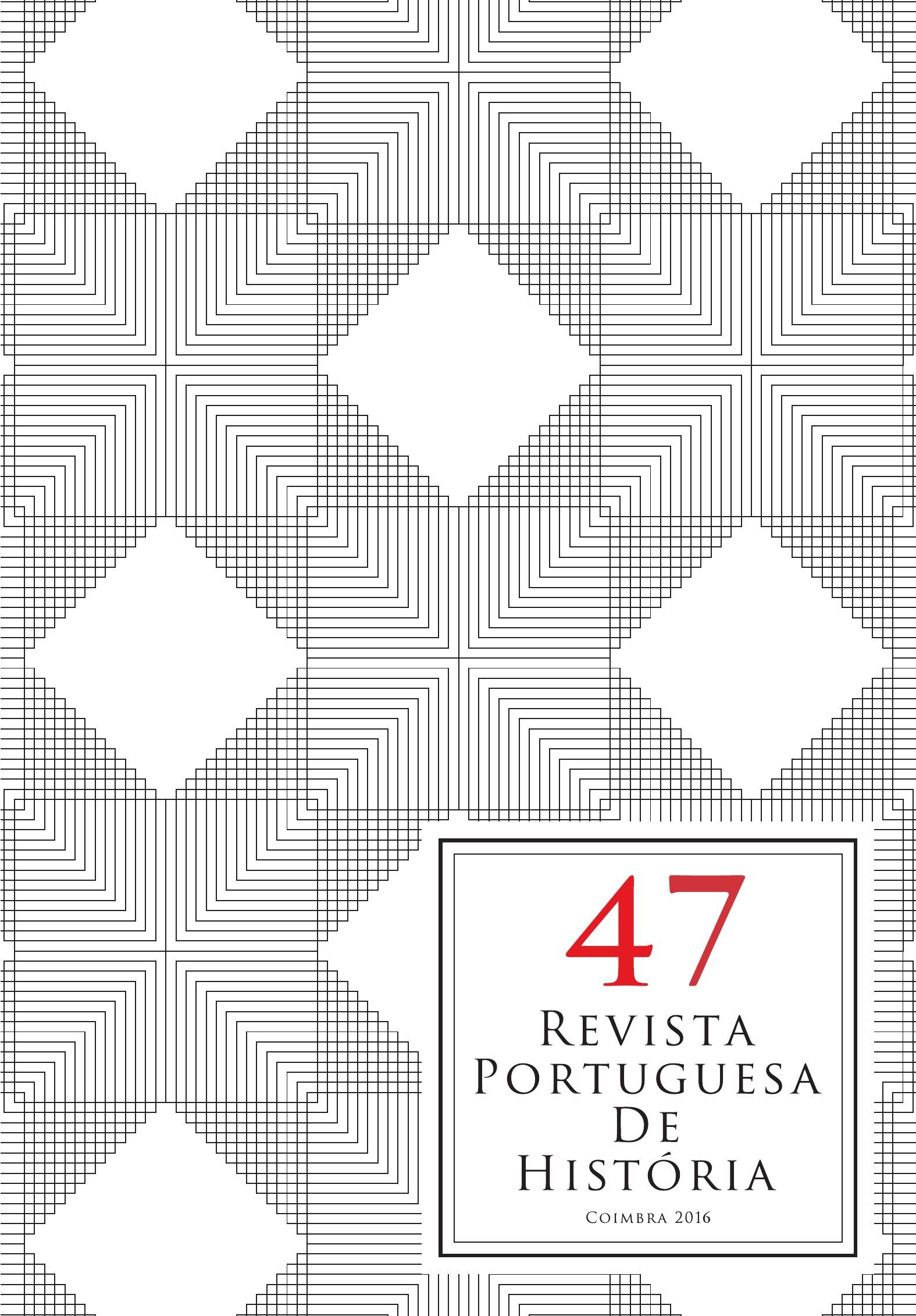




\title{
Aspetos do quotidiano e vivência feminina nos navios da carreira da Índia durante o século Xvi: primeiras mulheres, buscas e sexualidade a bordo
}

\author{
Aspects of the daily life and women living aboard the ships \\ of the carreira da Índia during the 16th century: the first women, searches \\ and sexuality on board
}

\author{
Marco Oliveira Borges \\ Centro de História da Universidade de Lisboa - UID/HIS/04311/2013 \\ Centro de Estudos Geográficos, IGOT, Universidade de Lisboa \\ marcoliveiraborges@gmail.com
}

Texto recebido em / Text submitted on: 31/01/2016

Texto aprovado em / Text approved on: 22/06/2016

Resumo:

Embora pouco reconhecida e estudada, a presença de mulheres a bordo dos navios da carreira da Índia foi uma realidade. É nosso objetivo contribuir para a continuação das investigações sobre este tema, analisando aspetos do quotidiano e dificuldades enfrentadas pelas mulheres nas viagens de ida e de volta da Índia durante o século XVI. Destacaremos as primeiras mulheres que embarcaram rumo ao Oriente, o pensamento que o homem tinha da mulher na época, as buscas feitas nos navios, bem como aspetos relacionados com a vida sexual e casamentos a bordo.

Palavras chave:

Carreira da Índia; Naus; Mulheres; Vida a bordo; Quotidiano.
Abstract:

Although it is little recognized and studied, the presence of women on board the Carreira da Índia was a reality. We aim to carry on the research on the topic, analysing aspects of the everyday life and the difficulties faced by women who travelled to and back from India during the $16^{\text {th }}$ century. We will emphasize the first women who sailed East, the thought men had about women at the time, the searches done on ships, as well as aspects related to sexual life and weddings on board.

Keywords:

Carreira da Índia; Ships; Women; Life on board; Everyday life. 


\section{Introdução}

Durante muito tempo a presença feminina nas narrativas historiográficas ligadas à Expansão Portuguesa dos séculos XVI-XVII foi praticamente inexistente. Aliás, de um modo geral, durante largo tempo as mulheres foram esquecidas da História ${ }^{1}$. Para fazer face a essa situação e mudar a direção do olhar histórico, algumas historiadoras enfatizaram que o importante não era centrar as atenções apenas numa história das mulheres, mas sobretudo na relação entre os dois géneros².

Em Portugal, foi na década de 1990 que arrancaram em força os estudos sobre a história das mulheres e que ganhou forma a sua presença no ensino superior ${ }^{3}$. No que respeita ao estudo da presença feminina na Expansão Portuguesa, um momento alto ocorreu em 1994, ano em que Lisboa acolheu um congresso internacional promovido pela Comissão para a Igualdade e para os Direitos das Mulheres, reunindo numerosos estudiosos. Com efeito, este encontro veio "a revelar uma face quase desconhecida da expansão portuguesa: a do seu rosto feminino". No ano seguinte vieram a lume as atas do congresso (2 vols.).

Entre os investigadores que ao longo do tempo abordaram a presença feminina na carreira da Índia, destacam-se os trabalhos pioneiros de Germano Correia, C. R. Boxer e Elaine Sanceau, os quais foram mostrando que a ausência das mulheres era uma das lacunas profundas e injustificáveis no seio da historiografia ultramarina portuguesa $a^{5}$. Outros investigadores posteriores foram trazendo importantes contributos para a compreensão da vida das mulheres embarcadas, alguns abordando a presença feminina de forma muito sumária, outros desenvolvendo mais as suas investigações, destacando-se os estudos de

${ }^{1}$ Anne Cova, "Escrever a História das Mulheres", in Actas dos V Cursos Internacionais de Verão de Cascais, vol. 4, Cascais, Câmara Municipal de Cascais, 1999, p. 117.

${ }^{2}$ Anne Cova, "Escrever...", cit., p. 118.

${ }^{3}$ Cf. Anne Cova, "Escrever...", cit., p. 119-129.

4 "Nota prévia", in O Rosto Feminino da Expansão Portuguesa. Congresso Internacional realizado em Lisboa, Portugal. 21-25 de Novembro de 1994, vol. I, Lisboa, Comissão para a Igualdade e para os Direitos das Mulheres, 1995, p. 15.

${ }^{5}$ Alberto Carlos Germano da Silva Correia, História da Colonização Portuguesa da Índia, 6 vols., Lisboa, Divisão de Publicações e Biblioteca Agência Geral das Colónias, 1948-1958; C. R. Boxer, "The carreira da Índia (ships, men, cargoes, voyages)", in O Centro de Estudos Históricos Ultramarinos e as Comemorações Henriquinas, Lisboa, [s.n.], 1961, p. 50-51; idem, A Mulher na Expansão Ultramarina Ibérica, 1415-1815. Alguns factos, ideias e personalidades. Trad. de Saúl Barata, Lisboa, Livros Horizonte, 1977; Elaine Sanceau, Mulheres portuguesas no ultramar. Trad. de Aureliano Sampaio, Porto, Livraria Civilização - Editora, 1979. 
Fina d'Armada ${ }^{6}$. De uma forma geral, entre estes autores ressalta a ideia de que a presença feminina na carreira da Índia é um tema ainda pouco explorado, mas de fundamental importância.

Neste estudo traremos um primeiro de outros contributos sobre a temática em discussão, sendo fundamental desde já a colocação de algumas questões prévias - algumas já apresentadas pela historiografia mas que merecem mais olhares - para as quais tentaremos trazer respostas: quem foram as primeiras mulheres (portuguesas ou não) que viajaram na carreira da Índia? Porque razões embarcaram nos navios? Sob que condição social? Como era vista a presença feminina a bordo face aos olhos dos homens da época? Quais as reações? De que modo a sua presença influenciou a vida a bordo? Em que locais do navio viajavam? Como se relacionavam com os homens? Outras questões e temas serão tratados futuramente.

A cronologia de trabalho está centrada no século XVI, sobretudo na primeira metade, se bem que um ou outro dado já nos remeta para o seguinte.

${ }^{6}$ Francisco Contente Domingues e Inácio Guerreiro, “A vida a bordo na Carreira da Índia (século XVI)", sep. da Revista da Universidade de Coimbra, XXXIV (1988), p. 22; Paulo Celso Miceli, O ponto onde estamos. Viagens e viajantes nas histórias da história da expansão e da conquista (Portugal, séculos XV e XVI). Tese de Doutorado apresentada ao Departamento de História do Instituto de Filosofia e Ciências Humanas da Universidade Estadual de Campinas, 1992, p. 244-249; idem, "«O zelo da virtude contra a peçonha do Diabo» - sospeitas, virtuosas e impudentes: a visibilidade feminina nas viagens portuguesas à época dos Descobrimentos", in O Rosto Feminino ..., cit., p. 187-196; Fina d'Armada, "As mulheres nas naus da Índia (séc. XVI)", in O Rosto Feminino..., cit., p. 197-230; idem, "As 35 navegantes da nau «S. Paulo» (1560-1561)", in Maria Helena Vilas-Boas e Alvim, Anne Cova, Elvira Cunha de Azevedo Mea (org.), Em torno da História das Mulheres, Lisboa, Universidade Aberta, 2002, p. 79-105; idem, Mulheres navegantes no tempo de Vasco da Gama, 2a ed., Lisboa, Ésquilo, 2007 [1 $1^{\mathrm{a}}$ ed., 2006]; António Lopes e Eduardo Frutuoso, "A vida a bordo nas naus da Carreira da Índia" (1995 e 2003) (http://nautarch.tamu.edu/shiplab/projects\%20ir\%20vidaabordo1.htm, consultado em 2014.05.27); Fábio Pestana Ramos, "Os problemas enfrentados no cotidiano das navegações portuguesas da carreira da Índia: fator de abandono gradual da rota das especiarias", Revista de História, 137 (1997), p. 77-94; Timothy J. Coates, Degredados e órfãs: colonização dirigida pela Coroa no Império Português, 1550-1755. Trad. de José Vieira de Lima, Lisboa, Comissão Nacional para as Comemorações dos Descobrimentos Portugueses, 1998, p. 193-195 e 205256; Amélia Polónia, "De Portugal al espacio ultramarino. Inclusión y exclusión femenina en la expansión ultramarina (siglo XVI)", in Dora Dávila Mendoza (coord.), Historia, género y familia en Iberoamérica (siglos XVI al XX), Caracas, Fundación Konrad Adenauer, 2004, p. 21 65 (https://books.google.pt/books?id=dTiOqBAPz4AC\&pg=PA2\&lpg=PA2\&dq=Dora+D\%C $3 \%$ A1 vila + Mendoza + (coord. $),+$ Historia, $+\mathrm{g} \% \mathrm{C} 3 \%$ A 9 nero $+\mathrm{y}+$ familia + en + Iberoam $\% \mathrm{C} 3 \% \mathrm{~A} 9 \mathrm{r}$ ica\&source=bl\&ots=KqkcHGZleG\&sig=juWNo_wrWruUXXjoldhY3Q-u0_s\&hl=pt-PT\&sa= X\&ved $=0$ ahUKEwjLjMjlyqfMAhVFNhoKHfrQAP4Q6AEIHjAA\# $\mathrm{v}=$ onepage \&q $=$ Pol $\% \mathrm{C} 3 \%$ B3nia\%2C\%20\&f=false, consultado em 2016.01.10). 


\section{A viagem}

A carreira da Índia foi a viagem marítima anual feita entre Portugal e os portos orientais e que chegou a ser considerada a maior e mais árdua do mundo ${ }^{7}$. A longa e dura jornada demorava perto de seis meses, estando sujeita a diversos perigos, a difíceis condições de vida a bordo e ao rigor climático de diferentes latitudes ${ }^{8}$. Na viagem para a Índia embarcavam centenas de pessoas em cada navio, estando a média à volta das 500 , sendo que alguns chegaram a transportar perto de $1.000^{9}$.

Habitualmente as armadas da Índia partiam de Lisboa entre o início de março e meados de abril. Depois de chegarem a área das ilhas de Cabo Verde, era norma que os pilotos infletissem para Sudoeste numa derrota que levava os navios até próximo da costa brasileira. Descaía-se depois para o rumo de Leste, a fim de alcançar o cabo da Boa Esperança, sendo que, caso este fosse dobrado na primeira quinzena de julho, aconselhava-se que se seguisse a chamada "viagem por dentro", a qual habitualmente levava os navios a fazerem escala em Moçambique. No caso em que os navios dobrassem o dito cabo depois de meados de julho, aconselhava-se a rota por fora da ilha de S. Lourenço. A chegada à Índia ocorria em finais de agosto ou já em setembro.

A torna-viagem tinha princípio em finais de dezembro ou inícios de janeiro, chegando as naus a Lisboa em fins de junho ou já em julho. Para as que partiam mais cedo era preferível a derrota pelo canal de Moçambique, enquanto que as retardatárias deveriam seguir a rota por fora. Ao passarem o cabo da Boa Esperança podiam fazer uma breve escala para abastecimento nas ilhas de Santa Helena e Ascensão ${ }^{10}$, sendo que a aproximação à costa africana era desaconselhada devido às calmarias da Guiné ${ }^{11}$. Era a Norte das ilhas de Cabo

${ }^{7} \mathrm{Cf}$. Alessandro Valignano S. I., Historia del principio y progresso de la Compañia de Jesús en las Indias Orientales (1542-64), Roma, Institutum Historicum S. I., 1944, p. 9-11.

${ }^{8}$ Cf. João de Barros, Ásia de João de Barros, seg. déc., liv. VII, [Lisboa], Imprensa Nacional-Casa da Moeda, 1988, cap. II, p. 315.

${ }^{9}$ Rui Landeiro Godinho, "Carreira da Índia", in Francisco Contente Domingues (dir.), Dicionário da Expansão Portuguesa. 1415-1600, vol. I, Lisboa, Círculo de Leitores, 2016, p. 221-222.

${ }^{10}$ Para uma perspetiva mais detalhada das rotas e dificuldades enfrentadas, cf. Alessandro Valignano S. I., Historia del principio..., cit., p. 10-11; Francisco Contente Domingues e Inácio Guerreiro, "A vida a bordo...," cit., p. 10-13; Luís de Albuquerque, "Carreira da Índia”, in Luís de Albuquerque (dir.), Dicionário de História dos Descobrimentos Portugueses, vol. I, [Lisboa], Caminho, 1994, p. 205; Rui Landeiro Godinho, "Carreira...", cit., p. 221-227.

${ }^{11}$ Diogo de Couto, Da Ásia de Diogo de Couto, déc. quarta, pt. I, Lisboa, Na Officina Typografica, 1778, p. 62. 
Verde que os navios vindos da Índia iniciavam a "volta pelo largo", que os levava até aos Açores, sendo que depois deste arquipélago os navios faziam uma escala final em Cascais e só depois rumavam a Lisboa ${ }^{12}$.

\section{As primeiras mulheres na carreira da Índia: presença e consequências}

A presença de mulheres a bordo de navios portugueses não constituiu qualquer novidade com o advento da carreira da Índia. Logo após ser tomada a decisão de que se deveria conservar Ceuta permanentemente, algumas mulheres portuguesas foram enviadas para aquela praça de guerra com os seus companheiros, situação que também aconteceu noutras fortalezas costeiras à medida que os portugueses se iam estabelecendo no Norte de África ${ }^{13}$. Algumas iam mesmo para as praças marroquinas sob a condição de degredadas ou como mancebas ${ }^{14}$.

Do mesmo modo, na vizinha Castela também chegaram a embarcar mulheres rumo ao Novo Mundo, se bem que isso tenha acontecido apenas a partir da terceira viagem de Cristóvão Colombo (1497-1498). Com efeito, sabe-se que a terceira armada castelhana transportou 30 mulheres rumo às Índias de Castela. A partir de então, todos os anos um grupo de castelhanas embarcava embora as estimativas quanto a um possível número não passem de conjeturas ${ }^{15}$.

Muito embora não existam registos documentais de mulheres que tenham participado na primeira viagem à Índia (1497-1499), isso não significa uma verdadeira ausência. O primeiro caso conhecido de mulheres embarcadas nos navios portugueses que rumavam anualmente ao Oriente remonta a 1502 . Durante a segunda viagem de Vasco da Gama à Índia, para a qual partiram 20 navios $^{16}$, Gaspar Correia diz que chegados à cidade de Quíloa (pequena ilha junto à costa da atual Tanzânia) os portugueses entraram em contacto com "muy fermosas mulheres" ${ }^{17}$. Uma vez maltratadas pelos mouros, estas optavam

${ }^{12}$ Sobre este assunto e as condicionantes geográficas que faziam de Cascais um porto fulcral no apoio a toda a navegação com destino a Lisboa, cf. Marco Oliveira Borges, O porto de Cascais durante a Expansão Quatrocentista. Apoio à navegação e defesa costeira. Dissertação de Mestrado em História Marítima, Universidade de Lisboa, 2012, p. 61-81 e passim.

${ }^{13}$ C. R. Boxer, A Mulher..., cit., p. [13].

${ }^{14} \mathrm{Cf}$., por exemplo, Documentos das Chancelarias anteriores a 1531 relativos a Marrocos. Ed. de Pedro de Azevedo, t. II, Coimbra, Imprensa da Universidade, 1915, p. 155-156.

${ }^{15}$ C. R. Boxer, A Mulher ..., cit., p. 43.

${ }^{16}$ Cinco deles para ficarem de armada junto às feitorias de Cananor e Cochim e, durante o verão, junto à boca do estreito do mar Roxo (cf. João de Barros, Ásia ..., cit., prim. déc., liv. VI, cap. II, p. 221).

${ }^{17}$ Gaspar Correia, Lendas da Índia. Introd. e rev. de M. Lopes de Almeida, vol. I, Porto, Lello \& Irmão - Editores, 1975, cap. IV, p. 282. 
por fugir e embarcar nas naus portuguesas com as suas filhas. Assim, com a conivência de alguns marinheiros, longe de terra há meses e "sedentos de amor feminino" ${ }_{18}$, mais de 200 mulheres foram escondidas cuidadosamente. Ao serem descobertas, estas alegaram que se queriam converter ao cristianismo, sendo que os próprios marinheiros portugueses haviam ajudado à elaboração dessa ideia. Esse seria um argumento útil para justificar a sua presença a bordo, já que, mesmo que escondidas nos navios, seria difícil deixar passar despercebida tanta mulher sem que se notasse, ainda que o cronista possa ter exagerado na quantidade enumerada. Contudo, Vasco da Gama, almirante e capitão-mor da armada, entendeu que essa suposta conversão não era o real motivo para quererem embarcar. Na verdade, a razão prendia-se com a necessidade de estas mulheres fugirem aos maus-tratos infligidos pelos seus maridos (mouros).

Deste modo, e vendo como era "grão incoueniente às consciencias dos homens, e pera outros defeitos andarem molheres em naos antre tantos homens, de que podem soceder tantos males, que serião peores ante Deos", Vasco da Gama ordenou trazer à sua nau todas as quiloenses e que fossem deixadas em terra, excetuando algumas meninas - caso houvessem - que "nom fossem tocadas d'homem". O almirante fez ver que a razão principal para deixá-las em terra tinha a ver com o perigo que podia surgir da "conuersação das molheres", pois a "cada hora andamos com a morte". Quem não cumprisse as ordens apregoadas nas naus e caravelas ficava sujeito à pena de morte ${ }^{19}$. Ou seja, perante tantos perigos que os marinheiros enfrentavam no quotidiano marítimo, sendo postos à prova de diversas maneiras, a presença de mulheres acabava por ser um meio de distração que podia vir a causar sérios problemas.

Contudo, Vasco da Gama, que havia entrado em Quíloa causando terror com o poder de fogo da artilharia dos seus navios ${ }^{20}$, ordenou que Gaspar da Índia, "lingoa" (tradutor) que seguia a bordo, avisasse o rei local de que estava proibido de tratar mal aquelas mulheres. Caso contrário, quando voltasse da Índia, quebraria a paz estabelecida e destruiria aquela cidade. Mas alguns mouros não quiseram as suas mulheres de volta, porque as mesmas alegavam já ser cristãs, sendo que isso veio a causar um diferendo religioso que as colocou em risco de morte. Assim, Vasco da Gama viu-se forçado a deixar embarcar 40 quiloenses na sua nau, ainda que nas "camaras fechadas" para que não ocorresse contacto com os homens portugueses. Uma vez chegadas à Índia, as

\footnotetext{
${ }^{18}$ Fina d'Armada, Mulheres navegantes..., cit., p. 158.

${ }^{19}$ Gaspar Correia, Lendas ..., cit., vol. I, cap. IV, p. 282-284.

${ }^{20}$ Tendo subjugado o rei local como vassalo de Portugal, obrigando-o a pagar um tributo anual em ouro (João de Barros, Ásia ..., cit., prim. déc., liv. VI, cap. III, p. 225).
} 
renegadas foram postas em Cananor e Cochim, sendo que as suas filhas foram as primeiras mulheres que daquelas partes viajaram para Portuga ${ }^{21}$. É possível que algumas se tenham casado com portugueses ${ }^{22}$.

Tem-se dito que as mulheres de Quíloa que entraram em contacto com os portugueses faziam parte de uma colónia muçulmana de raça branca ${ }^{23}$. No entanto, à semelhança do que acontecia em Mombaça e Melinde, locais não muito distantes e onde havia gente de "cor baça", branca e negra, incluindo as mulheres ${ }^{24}$, o agrupamento humano de Quíloa teria as mesmas características. Aliás, Duarte Barbosa confirma que, embora sendo uma terra dominada por mouros, estes eram "deles brancos, deles pretos" ${ }^{25}$. Para além disso, em 1506, três mulheres negras quiloenses serviam na fortaleza que os portugueses ali construíram ${ }^{26}$.

No que respeita à presença feminina portuguesa na carreira da Índia, costuma-se dizer que somente temos dados que nos mostram que algumas mulheres chegaram ao Índico em 1505. Contudo, na armada em que Lopo Soares retornou ao Reino nesse mesmo ano viajava D. Isabel Pereira, mulher de Henrique da Silveira ${ }^{27}$, pelo que teria de ter chegado à Índia pelo menos no ano anterior. $\mathrm{O}$ aspeto que se destaca neste caso tem a ver com o facto de que D. Isabel Pereira foi uma das pessoas que, nessa viajem de retorno, trazia pimenta a partido, ou seja, uma das modalidades de participação no comércio particular da Índia. É possível que o seu investimento neste comércio não se tenha esgotado aí. Note-se que, quanto aos partidos, não era obrigatório que o(a) priviligiado(a) com tal título esgotasse a oportunidade de participação numa única $v^{2} z^{28}$. Poderá não ter sido o único caso feminino, sendo que outras mulheres com um certo estatuto social poderão ter investido no trato das especiarias ao longo do tempo.

Ainda para 1505 temos dados que nos mostram a presença de portuguesas na costa oriental africana. No regimento deste ano que D. Manuel concedeu a

${ }^{21}$ Gaspar Correia, Lendas ..., cit., vol. I, cap. IV, pp. 282-284.

${ }^{22}$ Fina d'Armada, Mulheres navegantes..., cit., p. 161.

${ }^{23}$ Alberto Carlos Germano da Silva Correia, História da Colonização..., cit., vol. I, p. 229230; Fina d'Armada, Mulheres navegantes..., cit., p. 157.

${ }^{24}$ Cf. Duarte Barbosa, Livro em que dá relação do que viu e ouviu no Oriente [...]. Introd. e notas de Augusto Reis Machado, Lisboa, Agência Geral das Colónias, 1946, p. 23-24.

${ }^{25}$ Duarte Barbosa, Livro..., cit., p. 23.

${ }^{26}$ Vide infra, n. 35.

${ }^{27}$ ANTT, Núcleo Antigo, 913, fls. 29 e segs. apud M. Rosário S. Themudo Barata A. Cruz, O sistema de distribuição das cargas nas armadas da Índia, Lisboa, Instituto Nacional de Investigação Científica, 1988, p. 25 e 29.

${ }^{28}$ M. Rosário S. Themudo Barata A. Cruz, O sistema de distribuição ..., cit., p. 25. 
D. Francisco de Almeida para assumir o cargo de vice-rei da Índia, ordenava-se a passagem por Sofala, para a construção de uma fortaleza, da qual seria capitão Pedro de Anaia, bem como por Quíloa, onde se construiria outra, ficando a capitania a cargo de Pero Ferreira ${ }^{29}$. D. Francisco de Almeida partiu de Lisboa a 25 de março do dito ano, levando consigo uma armada de 14 naus e 6 caravelas, enquanto que Pero de Anaia zarpou a 18 de maio, como capitão-mor de 6 naus $^{30}$. Nesses navios vinham mulheres.

Após a construção da fortaleza de Sofala algumas portuguesas ficaram a servir no local. De 1 de março de 1506 surge um rol de pagamento do mantimento de fevereiro das pessoas destacadas na dita fortaleza, o qual dá conta de que 4 moradoras receberam um mitical de ouro: Isabel Pereira, Leonor, Inês Rodrigues e Brianda, sendo que a terceira detinha o estatuto de degredada ${ }^{31}$. Estas mulheres terão viajado na nau de Pero de Anaia, que ia com o propósito de fundar a fortaleza ${ }^{32}$, devendo desempenhar a função de vivandeiras ${ }^{33}$. Se nos casos de Isabel Pereira e de Inês Rodrigues não haverá dúvida quanto à sua vinda do Reino, no que respeita a Leonor e Brianda é incerto se também haviam tido a mesma origem geográfica. Porém, não surgindo referidas como "negras" ou "mouras", é provável que fossem portuguesas ${ }^{34}$. É que num rol de pagamentos do mês posterior, embora referido para a fortaleza de Quíloa, surgem alusões à existência de três mulheres "negras" (Isabel, Luzia e Violante), distinguindo-as assim das portuguesas ${ }^{35}$. Em todo o caso, e no que concerne a Sofala, é possível que outras portuguesas tenham ficado na fortaleza local mas tenham morrido anteriormente a 1 de março de 1506, pelo que não vieram referidas do rol citado. O mesmo se pode pensar no caso de Quíloa, tendo possivelmente falecido algumas mulheres antes de abril do referido ano.

Pela presença destas mulheres vindas de Portugal vê-se que desde cedo o universo feminino participou na expansão ultramarina oriental e que estas também foram agentes no processo de colonização.

${ }^{29}$ Pub. por A. B. de Bragança Pereira, Arquivo Português Oriental (Nova Edição), t. IV História Administrativa, vol. I - 1498-1599, pt. I, Bastorá, 1937, p. 16-28.

${ }^{30}$ Relações da Carreira da Índia. Navios da Carreira da Índia (1497-1653), códice anónimo da British Library. Governadores da Índia, pelo P.e Manuel Xavier, Lisboa, Publicações Alfa, 1989, p. 11-12.

${ }^{31}$ Documentos sobre os Portugueses em Moçambique e na África Central, vol. I, Lisboa, Centro de Estudos Históricos Ultramarinos, 1962, pp. 434-435 e 446-447.

${ }^{32}$ Fina d'Armada, Mulheres navegantes ..., cit., p. 309-310.

${ }^{33}$ Documentos sobre os Portugueses..., cit., vol. I, p. 446-447.

${ }^{34}$ Fina d'Armada, Mulheres navegantes ..., cit., p. 309-310.

${ }^{35}$ Documentos sobre os Portugueses..., cit., vol. I, p. 462-464. 
Das quatro mulheres de Sofala apenas duas ainda eram vivas em setembro de 1506, Isabel Pereira e Leonor, tendo as outras alegadamente sucumbido, uma vez que já não surgem em novo rol do pagamento de pessoas destacadas na fortaleza local ${ }^{36}$. Em fevereiro de 1507 ainda estavam vivas, aparecendo indicadas como as únicas mulheres presentes na referida fortificação ${ }^{37}$.

Uma das mulheres portuguesas que também embarcou em 1505 foi Iria Pereira, viajando solteira, mas esta acabou por chegar à Índia (Cochim) $)^{38}$. De acordo com Fina d'Armada, Iria Pereira viajou na nau Jerónimo, integrante da armada capitaneada por D. Francisco de Almeida. Esta mulher, contrariamente a muitas outras que ficaram anónimas nas fontes, acabou por ser referida por ser mãe de um homem que viria a ser importante na sua época: o piloto Diogo Pereira Botelho. O pai deste homem era António Real, capitão de Cochim, tendo viajado para a Índia junto de Iria Pereira ${ }^{39}$, a qual poderá ter sido igualmente acompanhada de outros familiares, estando assim protegida face à restante presença masculina ${ }^{40}$. É possível que, entretanto, Diogo Pereira Botelho, filho bastardo do tal António Real, tenha sido concebido no decorrer da viagem ${ }^{41}$. Inversamente a alguns casos que colocaram mulheres portuguesas na rota do Oriente, este viria a ser de sucesso já que Iria Pereira sobreviveu à viagem, haveria de ficar rica e com isso criar o filho "em muita vaidade"

Para além das quatro mulheres de Sofala e de Iria Pereira, é provável que outras tenham vindo na armada de 1505 . Ademais, é possível que na viagem de D. Isabel Pereira (1504) outras portuguesas tenham chegado à Índia, tal como poderá ter acontecido em anos anteriores, ficando dados ocultos na documentação da época. Note-se que nos navios iam embarcados muitos fidalgos e homens da casa do rei, os quais eram obrigados a servir por três anos na Índia ${ }^{43}$, pelo que decerto que alguns levariam as suas esposas ou outras mulheres (legal ou ilegalmente).

Em todo o caso, está por perceber até que ponto a presença feminina a bordo era tolerada pela Coroa. No tempo de Afonso de Albuquerque, o próprio

${ }^{36}$ Documentos sobre os Portugueses..., cit., vol. I, p. 644.

${ }^{37}$ Documentos sobre os Portugueses..., cit., vol. II, p. 160.

${ }^{38}$ Para uma visão mais detalhada deste caso, cf. Fina d'Armada, Mulheres navegantes..., cit., p. 204-220.

${ }^{39}$ Cartas de Affonso de Albuquerque seguidas de documentos que as elucidam, t. II, Lisboa, Typographia da Academia Real das Sciencias de Lisboa, 1898, p. 336; Diogo de Couto, Da Ásia [...], déc. quinta, pt. I, cap. II, p. 8.

${ }^{40}$ Fina d'Armada, Mulheres navegantes..., cit., p. 205-206.

${ }^{41}$ Fina d'Armada, Mulheres navegantes ..., cit., p. 213.

${ }^{42}$ Diogo de Couto, Da Ásia [...], déc. quinta, pt. I, cap. II, p. 8.

${ }^{43}$ João de Barros, Ásia ..., cit., prim. déc., liv. VIII, cap. III, p. 295. 
queixava-se de que D. Manuel não deixava mulheres portuguesas viajarem para a Índia ${ }^{44}$. Porém, já vimos que algumas embarcaram nos navios da carreira da Índia anteriormente a esse ano. Alguns casos mais tardios deixam perceber que os nobres e outros homens importantes teriam livre autorização para levar as suas mulheres ou outras para o Oriente, ou teriam de pedir licença régia quando assim o pretendessem, sendo que o resto dos embarcados não teria essa possibilidade. Em 1545, por exemplo, Jordão de Freitas pediu a D. João III que deixasse embarcar numa nau da Índia o seu irmão e a respetiva família: mulher, filha e filhos ${ }^{45}$. Esta família acabou por viajar para o Oriente, estando instalada naquelas partes pelo menos desde $1548^{46}$, se bem que as mulheres possam ter perecido na viagem.

Um momento crítico da presença feminina nos navios da carreira da Índia remete-nos para 1524, altura em que Vasco da Gama foi pela terceira ao Oriente, desta vez para assumir o cargo de vice-rei. Assim, no verão deste ano, estando a armada (14 navios) pronta para partir do porto de Belém, o vice-rei, sabendo do grande inconveniente que era o dos homens trazerem mulheres escondidas nas naus, "assy pera as almas como oniões e brigas", mandou apregoar em terra e nos navios as condições a que ambos estariam sujeitos caso as mesmas fossem descobertas a bordo:

1) Qualquer mulher que fosse encontrada nas naus depois da partida de Belém seria publicamente açoitada na Índia, mesmo que fosse casada. Consequentemente, o seu marido era obrigado a regressar a Portugal "carregado de ferros".

2) Se a mulher fosse escrava cativa, seria perdida para a rendição dos escravos.

3) Os capitães que encontrassem mulheres ou tivessem conhecimento da sua presença nas naus e não as entregassem perderiam os seus ordenados ${ }^{47}$.

Estas medidas denunciam que haveria alguma regularidade da presença feminina nos navios, incluindo mulheres casadas, se bem que antes de 1524 apenas tenham ficado registadas duas dúzias de portuguesas que desembarcaram

${ }^{44}$ Gaspar Correia, Lendas ..., cit., vol. II, cap. XLV, p. 375.

${ }^{45}$ Documentação para a História das Missões do Padroado Português do Oriente. Colig. e anot. por António da Silva Rego, vol. I, Lisboa, Agência Geral das Colónias, 1949, p. 531.

${ }^{46}$ Documentação para a História..., cit., vol. I, p. 562.

${ }^{47}$ Gaspar Correia, Lendas..., cit., vol. II, pp. 819-820; Francisco de Andrada, Crónica de D. João III. Introd. e rev. de M. Lopes de Almeida, Porto, Lello \& Irmão - Editores, 1976, cap. LIX, p. 155. 
na Índia ${ }^{48}$. Não admira que, nesse mesmo ano de 1524 , ao chegarem a Moçambique (local de escala), fossem descobertas 3 mulheres a bordo dos navios, as quais Vasco da Gama mandou “arrecadar". Por elas foram rogadores todos os fidalgos, o bispo, os frades e os da Misericórdia, sendo que houve homens que se disponibilizaram a dar 3.000 pardaus para a rendição dos cativos caso as mulheres não fossem castigadas, mas Vasco da Gama não cedeu a qualquer pressão. Fernão Lopes de Castanheda, que refere apenas duas mulheres solteiras descobertas, acrescenta que dois homens propuseram-se a casar com elas, mas que recusavam caso as mesmas fossem açoitadas ${ }^{49}$. Não se sabe se estes indivíduos estiveram envolvidos na vinda clandestina das mulheres, é apenas uma hipótese, mas alguém teve que as esconder e alimentar durante aqueles meses de viagem.

As mulheres acabariam por ser açoitadas já em Goa, como forma de exemplo, desagradando aos homens que assistiram a tal ato de violência. Vasco da Gama, que ficou visto como "cruel", terá referido que se não fizesse "enxecução n'estas molheres, que desprezarão sua justiça, muyto melhor farião os homens confiando que os perdoaria de seus malefícios" ${ }{ }_{50}$. Assim, a inflexibilidade do vice-rei também se prendeu com outros assuntos delicados do Estado da Índia e a necessidade de cumprir a legislação perante qualquer tipo de crime, sendo que "o temor daquella justiça fez então emendar muytos males que auia na India, principalmente na gente nobre, em que auia muyta soltura e dissoluções" ${ }_{51}$. Acresce que na própria viagem de 1524 tinham ocorrido graves atos de insubordinação. Note-se que a tripulação da caravela capitaneada por Mosen Gaspar revoltou-se e deslocou-se para o Estreito em atividades corsárias ${ }^{52}$. Somente com pulso de ferro e aplicação de penas severas era possível fazer justiça e criar medo entre os homens, para que tais ações não se voltassem a repetir, não podendo Vasco da Gama mostrar falta de autoridade. De referir que a caravela insubordinada acabaria por ser tomada por António Miranda e levada para a Índia, onde foi ordenado que todos fossem enforcados ${ }^{53}$.

A 18 de abril de 1528 partiu para a Índia uma armada de 11 navios com perto de 4.000 homens, estando igualmente inserida no âmbito da luta contra

${ }^{48}$ Fina d'Armada, Mulheres navegantes..., cit., p. 166.

${ }^{49}$ Fernão Lopez de Castanheda, Historia do descobrimento e conquista da India pelos portugueses, liv. VI, Lisboa, Na Typographia Rollandiana, 1833, cap. LXXI, p. 154.

${ }^{50}$ Gaspar Correia, Lendas ..., cit., vol. II, p. 820-821.

${ }^{51}$ Francisco de Andrada, Crónica..., cit., cap. LIX, p. 156.

${ }^{52}$ Luís Adão da Fonseca, Vasco da Gama. O homem, a viagem, a época, Lisboa, Comissariado da Exposição Mundial de Lisboa, 1997, p. 73-74.

${ }^{53}$ Gaspar Correia, Lendas ..., cit., vol. II, p. 816. 
os turcos. Já perto das Canárias, e por teimosia de um piloto em não se querer desviar, uma nau abalroou outra causando um naufrágio. Apesar de algumas pessoas terem sido salvas, acabaram por morrer 150 afogadas. Entre as vítimas estava um homem casado que levava a sua mulher e três filhas moças ${ }^{54}$. Estas foram quatro mulheres que não passaram o Atlântico, mas muitas mais, noutras viagens ao longo do tempo, terão perecido ainda no "Mar Oceano" por diversas causas.

Quantas mulheres viajariam nesta armada de 1528 ? Embora não existam fontes que permitam responder a esta questão, várias mulheres partiram para o Oriente nesse ano. Quem o refere é o dominicano castelhano fr. Vicente de Laguna, o qual indo embarcado e estando indignado com tal situação, escreveu de Goa (25 de setembro de 1530) uma carta a D. João III em que também dava conta deste assunto. Segundo Laguna, tanto os capitães como os pilotos, os mestres e os marinheiros, traziam mulheres nas naus ${ }^{55}$.

Dois anos volvidos, numa outra carta dirigida ao rei (29 de novembro), Laguna alude à vinda de navios "cargados de molheres" $"$. Apesar de outra carta deste ano (12 de dezembro) referir que existiam penas decretadas pelo rei para quem trouxesse mulheres a bordo ${ }^{57}$, a verdade é que as mesmas continuavam a embarcar com a conivência dos oficiais de bordo. Assim, em 1532, por exemplo, Aldonça Ferraz, casada com Pedro Gomes de Abreu (fidalgo), veio à Índia numa nau partida de Lisboa a 9 de abril ${ }^{58}$.

Dos casos vistos até agora percebe-se que, apesar das proibições, alguns nobres ou indivíduos importantes conseguiam autorizações para levar mulheres para a Índia. Inversamente, quando não tinham acabariam por levá-las clandestinamente. Outros homens (nos quais também se podiam incluir capitães, pilotos, armadores, etc.) levavam ilegalmente mulheres embarcadas, contando para isso com a conivência uns dos outros.

\section{A visão que o homem tinha da mulher na época e as buscas a bordo}

Se para alguns a existência de mulheres a bordo não levantava grandes problemas, para outros era um "grão inconuiente às consciências dos homens", sendo que a sua presença no seio de uma tripulação exclusivamente masculina

\footnotetext{
${ }^{54}$ Diogo de Couto, Da Ásia [...], déc. quarta, pt. I, liv. V, cap. I, p. 325-328.

${ }^{55}$ Documentação para a História ..., cit., vol. II, p. 193.

${ }^{56}$ Documentação para a História..., cit., vol. II, p. 231.

${ }^{57}$ Documentação para a História ..., cit., vol. II, p. 236.

${ }^{58}$ Alberto Carlos Germano da Silva Correia,. cit., vol. II, p. 47.
} 
poderia causar "tantos males" 59 . Em 1528, conforme foi dito, várias mulheres partiram para o Oriente. Segundo fr. Vicente de Laguna, tanto os capitães como os pilotos, os mestres e os marinheiros, traziam-nas nas naus, situação que levava a grandes contendas a bordo e a que os homens se deixassem dormir ${ }^{60}$. Ou seja, além das disputas que deveriam surgir e do tempo gasto na "atenção" dada às mulheres, os homens faziam mal as suas vigias, revelavam atitudes negligentes e descuidavam-se noutros aspetos de segurança, podendo levar a acidentes a bordo ou até a naufrágios. O exemplo específico que o dominicano dá está na utilização descuidada dos candeeiros, que funcionavam com fogo, sendo que todos queriam tê-los debaixo da ponte e nas suas câmaras. Durante a viagem tal negligência levou a dois fogos na nau em que vinha, mas, por milagre, as chamas não se alastraram, não havendo grandes estragos e pessoas mortas. É neste contexto que as mulheres acabavam por ser consideradas as grandes responsáveis pelos vários incêndios que muitas vezes conduziam à perda de navios ${ }^{61}$.

As tensões geradas pela presença feminina levavam a problemas de ordem disciplinar, resolvidos com o isolamento das mulheres ou, por vezes, desembarcando-as na primeira oportunidade (no caso das que viajavam clandestinamente) ${ }^{62}$. O Pe ${ }^{\mathrm{e}}$. Sebastião Gonçalves, numa carta de 10 de setembro de 1562, refere mesmo que durante as buscas, feitas logo no primeiro dia, procurava-se "botar fora da nao a peçonha que o diabo costuma introduzir pera perdição dos navegantes". Na viagem desse ano, "duas molheres sospeitosas" acabaram por ser postas fora do navio em que o dito padre viajava, havendo vontade de que outras das quais se tinha suspeita tivessem semelhante destino ${ }^{63}$. Parece que isto ocorreu ainda antes da largada de Lisboa.

Deste caso há um aspeto que salta à vista, parecendo que a expressão "molheres sospeitosas" era usada para distinguir aquelas que eram solteiras das que eram casadas. Estas mulheres estavam associadas, segundo a correspondência dos padres jesuítas, à prostituição a bordo, à origem de distúrbios, à falta de segurança, à destruição de costumes e à indisciplina, sendo por isso sujeitas a castigos ou largadas nalgum local de escala da viagem ${ }^{64}$. Apesar de, no geral, a presença feminina descontentar os missionários, eram as mulheres solteiras que constituíam o mal maior porque acabavam por juntar-se

\footnotetext{
${ }^{59}$ Gaspar Correia, Lendas ..., cit., vol. II, p. 282-284.

${ }^{60}$ Documentação para a História ..., cit., vol. II, p. 193.

${ }^{61}$ Paulo Miceli, “«O zelo da virtude...", cit., p. 188.

${ }^{62}$ Francisco Contente Domingues e Inácio Guerreiro, “A vida a bordo...”, cit., p. 204.

${ }^{63}$ Documentação para a História ..., cit., vol. IX, p. 60.

${ }^{64}$ Amélia Polónia, "De Portugal al espacio ultramarino...”, cit., p. 24.
} 
- já na Índia - com homens casados e arruinar casamentos, desagradando fortemente aos olhos da Igreja ${ }^{65}$. A comprovação do estado civil solteira, levada a cabo pelas diligências dos missionários, facilitaria a pressão exercida perante os capitães dos navios para que fossem largadas em terra, a não ser que algum homem fizesse oposição e, falando verdade ou mentira, dissesse que a mulher em causa era sua esposa. Pode ter sido isso também que aconteceu neste caso de 1562 , tanto mais que havia suspeita sobre outras mulheres que seguiam a bordo, mas essas não foram largadas em terra.

Outros motivos levavam os missionários a queixarem-se da presença feminina a bordo. Em 29 de novembro de 1532, numa das cartas que dirigiu a D. João III, Fr. Vicente de Laguna chegou a alegar que as naus transportavam alimentos e água em insuficiência para a viagem até à Índia porque iam carregadas de mulheres ${ }^{66}$.

Conforme se vê, eram, sobretudo, os padres que estavam empenhados em que a presença feminina a bordo das naus fosse proibida, praticando buscas e perseguições desde o início ao fim da viagem ${ }^{6}$. Note-se que, além dos ofícios da religião (missas, procissões e confissões), do tratamento dos doentes, do combate ao jogo, às blasfémias e à leitura de livros profanos, os padres tinham na procura das mulheres embarcadas uma das suas principais missões ${ }^{68}$. A busca desenfreada e obsessiva chegava a espantar o pessoal de bordo, mesmo aqueles que estavam acostumados à presença dos missionários nos navios. No citado caso de 1562 chegou mesmo a pensar-se que o padre Vicentio, indo "tão aceso" nas buscas, tinha alguma doença, situação que levou o capitão do navio a averiguar o caso e a mostrar que não tolerava tal atitude ${ }^{69}$.

No quotidiano da vida a bordo era frequente que os homens se exercitassem em confissões, mas com a presença feminina essa necessidade acabava por aumentar. A 13 de dezembro de 1548, o padre jesuíta Gaspar Barzaeus referia que os homens tinham que se exercitar "en confesiones y en hazer amonestaciones, aviendo desto grande necesidade, por las muchas mugeres que en la nao venían". Por isso mesmo, ele e os outros padres embarcados haviam determinado pedir ao capitão que as deixasse em terra, se nalguma parte

${ }^{65}$ Desenvolveremos a presença de mulheres de diferentes condições sociais na carreira da Índia num próximo trabalho, tal como a sua presença em naufrágios, combates, etc.

${ }^{66}$ Documentação para a História ..., cit., vol. II, p. 231.

${ }^{67}$ Documenta Indica, vol. I, p. 155; Documenta Indica, vol. V, p. 569-570.

${ }^{68}$ Paulo Miceli, “«O zelo da virtude...”, cit., p. 187; Liam Matthew Brockey, “Jesuit missionaries on the carreira da Índia in the sixteenth and seventeenth centuries. A selection of contemporary sources", Itinerario, 31, 2 (2007), p. 111-132.

${ }^{69}$ Documentação para a História ..., cit., vol. IX, p. 60. 
viessem a ancorar ${ }^{70}$. A nau em causa era a $S$. Pedro, que vinha como capitania. Mais adiante, o mesmo padre diz que durante uma tormenta, já no Índico, tratou de confessar as mulheres, mas uma delas, mesmo perante forte insistência, recusou-se confessar e afastar-se "de sus malas costumbres passadas". Contudo, a mulher acabaria por ser amedrontada com a ideia de rumar ao inferno caso não se confessasse, pelo que acabou por ceder ${ }^{71}$.

A deteção de mulheres a bordo podia levar, por diferentes motivos, a que fossem transferidas para um navio diferente daquele em que vinham embarcadas. $\mathrm{Na}$ armada de 1555, por exemplo, ao que parece já na costa da Guiné, apareceu uma mulher de "mao viver" que vinha "escondidamente". Como "avia alguns inconvenientes ir nela", o capitão-mor mandou transferi-la para a nau Ascensão, "aonde lhe fizerão hum camarote e a fecharão com muito resguardo" "?. Uma vez chegada à Índia, ficou na casa de uma mulher casada que aparentava ser boa pessoa. Parece que esta mulher que vinha escondida terá aparecido sem que fosse descoberta nalguma busca a bordo, não se sabendo qual o contexto que a levou a sair do "esconderijo" em que vinha.

Uma questão que importa frisar tem a ver precisamente com os locais em que as mulheres viajavam. Se aquelas que acompanhavam os seus maridos - especialmente as nobres - poderiam partilhar a mesma câmara ou camarote, mais frequentemente à popa da nau, com janelas ou acesso a uma varanda ${ }^{73}$, tal como podia acontecer a outras que viessem protegidas por homens importantes, algumas, vindo (mais) clandestinamente, não tinham tanta sorte. Teriam de viajar fechadas em compartimentos ou esconderijos ainda mais pequenos e em condições que muito mais facilmente tornariam a jornada penosa e que poriam a sua vida em risco. Por outro lado, algumas mulheres embarcavam vestidas de homem, esperando que não fossem notadas entre os passageiros, mas o disfarce poderia ser de pouca dura e a sua deteção conduzir a que fossem desembarcadas nalgum porto $^{74}$.

\section{Casamentos e atividade sexual a bordo}

Apesar da forte contestação e perseguição dos padres às mulheres chegaram a ocorrer romances e casamentos em pleno mar. Em 1545, um romance vivido

\footnotetext{
${ }^{70}$ Documenta Indica, vol. I, p. 384.

${ }^{71}$ Documenta Indica, vol. I, p. 388-389.

${ }^{72}$ Documentação para a História ..., cit., vol. VI, p. 55; Documenta Indica. vol. III, p. 385-387.

${ }^{73}$ Vide infra, n. 83 e 84.

${ }^{74}$ Documentação para a História ..., cit., vol. IX, p. 446.
} 
na nau Burgalesa terminou em casamento. A história ligou um cavaleiro que se apaixonou pela filha de um outro passageiro ilustre e que pediu a sua mão em casamento. Porém, a celebração teve lugar apenas em Goa ${ }^{75}$. Contrariamente, na viagem de 1562 ocorreram dois casamentos numa nau. O primeiro deles teve o consentimento de todos, por não se registar qualquer impedimento, enquanto que o segundo ocorreu clandestinamente, em virtude de o capitão do navio ter proibido tal união "por aver alguma sospeita de cunhadio, porquanto elles avião dito que erão cunhados e, depois, não podião provar o contrario" ${ }^{\prime}$.

Como se desenrolava a vida sexual a bordo de um navio que partia para a Índia transportando centenas de homens, poucas mulheres, e que, em média, demorava perto de seis meses a finalizar a viagem? Sobre este tema, como seria de esperar, as fontes não são muito expressivas. Porém, adivinha-se com facilidade, e comprova-se com alguns dados disponíveis, que os mais afoitos tentavam toda a sorte de expedientes "para se aproximarem das mulheres embarcadas, por vezes com consequências trágicas ou então simplesmente caricatas" "?

Se a presença feminina a bordo era proibida, ainda que capitães, pilotos e outros marinheiros fizessem vista grossa às ordens régias e ajudassem a embarcar e a esconder mulheres, o aliciamento, prática e deteção flagrante de sujeitos e sujeitas em atos sexuais poderia levar a pesadas consequências para os visados e até mesmo à morte. No tempo de Afonso de Albuquerque, Rui Dias, português de boa linhagem oriundo de Alenquer, foi apanhado na câmara da nau do governador com uma escrava. O caso ocorreu no Oriente, embora não tenha sido num navio que fazia a carreira da Índia. O trecho de João de Barros é confuso ${ }^{78}$, não se percebendo se Rui Dias foi apanhado ou não em flagrante sexual com a mulher, mas a pena de enforcamento a que foi rapidamente condenado sugere que tenha sido algo grave, sendo que nem o apelo de outros portugueses fez Albuquerque recuar.

Vivendo num universo de promiscuidade em que praticamente não havia privacidade, excetuando no caso daqueles que tinham compartimentos dos navios reservados, é muito provável que tenham sido frequentes as situações de flagrante sexual e consequente aplicação de castigos, se bem que muitas também devam ter sido abafadas e nem sempre penalizadas. Paulo Miceli refere que, apesar de escassas, as referências documentais às mulheres de "mau viver" ou

\footnotetext{
${ }^{75}$ António Lopes e Eduardo Frutuoso, “A vida a bordo...”, cit., s/p.

${ }^{76}$ Documentação para a História ..., cit., vol. IX, p. 61.

${ }^{77}$ Francisco Contente Domingues e Inácio Guerreiro, “A vida a bordo...”, cit., p. 22.

${ }^{78}$ João de Barros, Ásia..., cit., seg. déc., liv. V, cap. VII, p. 219-220.
} 
àquelas que eram suspeitas são suficientes para se afirmar que estas viagens também foram acompanhadas "por uma espécie de prostituição flutuante". O investigador diz que essa prostituição seria praticada possivelmente "nos intervalos dos duros trabalhos do mar, tantas vezes acidentados e tempestuosos, pelos cantos e esconderijos que a caixaria amontoada não entupia de todo" 7 .

Parece-nos, no entanto, que as mulheres que iam como prostitutas estavam apenas ao alcance de um pequeno grupo de homens onde se incluíam os capitães, os pilotos, mestres e armadores, a não ser que, por vezes, eles não tivessem conhecimento da sua presença ou permitissem o contacto com homens comuns. Por outro lado, muitas mulheres que ficaram conotadas com a prostituição poderiam vir apenas como mancebas. Por carta de 12 de dezembro de 1532, o bispo D. Fernando Vaqueiro queixou-se ao rei de que tinha viajado muito desgostoso para a Índia devido a Vicente Gil (armador da nau Graça) vir "publicamente amançebado", consentindo que alguns oficiais viessem na mesma situação. O bispo repreendeu Vicente Gil por várias vezes, até porque o escrivão da nau lhe requereu que se apartasse a si e aos outros de tal situação, mas a verdade é que o homem não ligou ao que era dito nem às penas que $\mathrm{D}$. João III tinha decretado para quem trouxesse mulheres a bordo ${ }^{80}$.

Portanto, apesar da legislação, mulheres eram embarcadas, havendo mancebas e prostitutas a bordo. No que respeita à prostituição, esta seria uma atividade controlada e não desenfreada, levada a cabo em certos locais que aqueles poucos homens tinham acesso. Esta situação das prostitutas estarem apenas disponíveis para um pequeno grupo de homens acabaria por ser um enorme problema e podia gerar conflitos graves, visto que muitos dos que tinham conhecimento da sua presença ou que testemunhavam atos sexuais também sentiam necessidade de satisfazer os seus impulsos. Não conseguindo comprazer o desejo sexual com aquelas que iam embarcadas, os homens que viajavam para o ultramar tinham que esperar até que os navios fizessem escala nalgum local e pudesse haver contacto com alguma moura ou negra ${ }^{81}$, situação que levava meses. Contudo, é possível que devam ter havido momentos de maior liberdade em que as mulheres possam ter estado envolvidas com um número mais elevado de homens e em espaços à vista de muitos outros, se bem que

${ }^{79}$ Paulo Miceli, “«O zelo da virtude...”, cit., p. 189.

${ }^{80}$ Documentação para a História ..., cit., vol. II, p. 236.

${ }^{81}$ Amândio Jorge Morais Barros, "Vida de marinheiro. Aspectos do quotidiano das gentes do mar nos séculos XV e XVI", in F. Ribeiro da Silva et al. (org.), Estudos em Homenagem a Luís António de Oliveira Ramos, vol. I, Porto, Faculdade de Letras da Universidade do Porto, 2004, p. 260. 
esse fosse um fator para maior desordem a bordo e perigo quanto à navegação, daí também as sucessivas queixas dos missionários.

No entanto, é preciso atenuar um pouco a questão da prostituição, visto que nem todas as "molheres suspeitosas" eram prostitutas. Por outro lado, e embora numa condição social diferente, sendo esposas de homens importantes, órfãs, etc., outras mulheres poderiam vir a ter problemas com homens durante o percurso. Viajando num universo de centenas de indivíduos, muitos deles criminosos de delito comum saídos das prisões, aquelas que não viajassem na proteção dos seus maridos ou de homens importantes poderiam ser alvo de um assédio desenfreado. Mesmo as que vinham na companhia dos maridos e que, com o decorrer da viagem, ficavam viúvas, poderiam a partir daí ser um alvo fácil.

Em 1608, na atribulada e trágica viagem da nau Nossa Senhora da Salvação, que naufragou na costa de Mombaça, iam embarcadas três órfãs do Recolhimento do Castelo de Lisboa, estando confiadas a uma passageira de consideração. O capitão da nau, D. Luís de Sousa, andou desinquietando as órfãs, tanto a bordo como em Mombaça, onde a tripulação se acolheu depois do naufrágio. Acabou por ser ordenada uma averiguação, a propósito do comportamento do impulsivo capitão e de este pretender devassar o recato das jovens passageiras, uma das quais acabou por morrer durante a viagem. A bordo da nau seguia igualmente um embaixador do rei da Pérsia, o qual foi assaltado pelos fidalgos, que tomaram o seu dinheiro à força. Por estes incidentes, pelo naufrágio da nau e possivelmente por outros que ficaram por conhecer, o capitão D. Luís de Sousa andou homiziado ${ }^{82}$.

Tentando procurar e entrar em contacto com mulheres clandestinas ou que vinham isoladas e sob proteção, alguns homens poderiam entrar em situações bastante caricatas e ser alvo do registo escrito dos missionários da época. Vejase, por exemplo, o caso de um homem morto por ferimentos de um tubarão depois de se ter atirado ao rio para ver melhor as mulheres que seguiam a bordo de uma nau:

"Morreram muitos [durante a viagem para a Índia] entre os quais foi um mancebo que, andando nadando no rio, e segundo alguns diziam era pera ir ver umas molheres que estavam em a varanda do leme [do navio], e andando assi nadando veio hum tubarão que lhe levou huma coxa da perna que lhe não deixou mais que o osso e assi hum pedaço de hum braço. Acudiram-lhe loguo e o trouxeram pera a terra, onde

${ }^{82}$ Livro das Monções, 4. ${ }^{\circ}$, fl. 30 e 36; 6. ${ }^{\circ}$, fl. 191 apud Quirino da Fonseca, Os portugueses no mar, vol. I, [Lisboa], [s.n.], 1926, p. 452. 
o enterraram e queira Nosso Senhor que estivesse confessado, ou ao menos com contrição dos seus pecados e esperança de misericordia a hora da sua morte. Aqui verão, charissimos irmãos quanto bem he estar em graça com Nosso Senhor e aparelhados pera todas as horas" ${ }^{\prime 3}$.

O caso remonta a 1562, altura em que se fazia escala em Moçambique. É muito provável que estas mulheres que o homem tentava ver fossem "orfãs d'El-Rei”, donzelas que, geralmente, iam "ao cuidado de senhoras da nobreza, o que não impedia que a sua presença suscitasse uma curiosidade enorme entre a tripulação e demais passageiros. Para evitar situações problemáticas daí decorrentes, viajavam fechadas num camarote da nau, geralmente à popa, com acesso a uma varanda" ${ }^{84}$.

No meio de centenas de homens embarcados, e face a restrições de contactos com as poucas mulheres presentes ou até mesmo à sua ausência, o onanismo e a homossexualidade acabavam por ser frequentes, havendo dados sobre esta última prática e execuções punitivas a bordo ${ }^{85}$.

\section{Conclusão}

A presença feminina nas naus da Índia até meados do século XVI parece constante, tendo alternado entre a clandestinidade (com ou sem a conivência dos oficiais de bordo) e a "legalidade" mediante autorização régia. Enquanto que alguns nobres e homens importantes conseguiam autorização do rei para transportar as suas mulheres, filhos e filhas, outros, apesar das severas punições a que estavam sujeitos, traziam esposas, amantes ou prostitutas sem qualquer tipo de permissão.

Para além das mulheres que rumavam à Índia nas naus, outras eram levadas para as fortalezas da costa oriental africana, integrando o processo de colonização próprio da Expansão Portuguesa. Não obstante as proibições, algumas alcançaram diversas partes dominadas pelos portugueses numa época ainda recente da expansão no Índico.

Estas mulheres, quando surgem referidas, aparecem quase sempre como figuras problemáticas, causadoras de acidentes e de instabilidade a bordo, havendo a necessidade de as deixar no porto mais próximo. Eram os padres

${ }^{83}$ Documentação para a História ..., cit., vol. IX, p. 72.

${ }^{84}$ António Lopes e Eduardo Frutuoso, “A vida a bordo...”, cit., s/p.

${ }^{85}$ Cf., por exemplo, Documentação para a História..., cit., vol. IV, p. 82-83; Fábio Pestana Ramos, "Os problemas...", cit., p. 78 e 85; Amândio Jorge Morais Barros, "Vida de marinheiro...", cit., p. 260-261. 
que se preocupavam mais com a sua presença no navios, sendo que, para além de passarem a escrito alguns acontecimentos ou ideias que descredibilizavam a essência feminina, desde o início e ao longo das viagens que faziam buscas para se certificarem de que não vinham embarcadas. O problema maior acabava por estar nas que vinham solteiras, algumas amancebadas, outras como prostitutas.

Inversamente, outros homens arriscavam e procuravam indagar sobre a existência de mulheres nos navios na esperança de que pudessem ter algum contacto e relacionamento sexual. Se em determinados momentos a prostituição a bordo foi uma realidade, embora seja de crer que esta fosse uma atividade quase exclusivamente restrita aos homens importantes (nobres, capitães, pilotos, armadores, etc.), por outro lado, alguns destes homens poderiam transportar as suas esposas ou amantes na câmaras dos navios, tendo chegado a ocorrer casamentos em pleno mar.

Um dos aspetos importantes abordados, e que precisa de ser melhor compreendido, é o de as próprias mulheres poderem investir no comércio das especiarias orientais, como se viu no caso de D. Isabel Pereira, se bem que isso estaria exclusivamente ao alcance das que tinham um certo estatuto social.

Finalizando, as novas interpretações e possibilidades aduzidas ao longo do texto permitem ir um pouco mais além no conhecimento, colocando igualmente diversas dúvidas e questões que ajudarão a conduzir as investigações futuras e a explorar outros temas pouco estudados, prevendo-se ainda retomar algumas das questões centrais colocadas inicialmente. 